\section{P-210 MAN SHED - EXTENDING THE REACH AND ENGAGING} THE COMMUNITY

Kathy Birch, Martin Osborn, Julia Russell. Princess Alice Hospice, Esher, UK

\subsection{6/bmjspcare-2017-hospice.235}

Background Historically certain groups of people have been less likely to access hospice support, for example of every three women accessing bereavement support only one man did. Men's Sheds have grown in popularity but only one hospice had a shed specifically for people affected by life-limiting illnesses.

Aims

- To provide alternative support for patients, carers and bereaved relatives

- To diversify volunteering roles

- To demystify hospice care by engaging the local community.

Methods A cross-organisational steering group of staff, volunteers and users was formed and a fundraising project launched which exceeded $£ 112000$. Plans were agreed and a $12.5 \mathrm{~m} \times$ $5.5 \mathrm{~m}$ structure was built by contractors to accommodate a fully functioning wood workshop and social area designed and fitted out by volunteers. Health and Safety, Facilities, Volunteering and Education teams supported induction processes, development of risk assessments and training.

Results

- Cross-organisational project brought together clinical and non-clinical staff and volunteers

- New roles have been created for volunteers

- New links have been forged with businesses and the local community donating wood and consumables

During the first nine months:

- six volunteers have been recruited and trained to lead sessions

- one volunteer provides administrative support, one volunteer ambassador sources equipment and consumables

- Opens three days a week

- 53 'shedders' have been referred, resulting in 357 attendances.

- Patients, carers and bereaved relatives have attended woodworking sessions

- A basic computer literacy course has taken place

- Feedback is positive and the service valued by people who would not have accessed traditional services

- Items produced have raised funds to sustain the project

- A local woodcarving group also uses the building.

Conclusions The Man Shed has created opportunities for people to be offered 'shoulder-to-shoulder' support while engaging in practical activities. This informal approach has helped to break down pre-conceived barriers and misconceptions about hospice care. A number of other hospices are now planning their own sheds.

\section{P-211 THE NURSE LED MODEL OF HOSPICE INPATIENT CARE - 7 YEARS ON}

Dinah Hickish. St Kentigern Hospice, St Asaph, UK

10.1136/bmjspcare-2017-hospice.236
Hospices across the UK are having to re-examine the way their services are run as pressure on funding is becoming increasingly problematic in a nation that has fiscal uncertainty. In Wales statutory funding for hospices is arrived at by a formula and St Kentigern Hospice receives 18\% of its funding from the Welsh Office.

The hospice hit financial crisis in 2010 and took drastic measures with swingeing cuts to services, including the decision to make the medical director and sole doctor redundant. A decision was made that St Kentigern Hospice would become a nurse- led unit in the faint hope that this would save the hospice. This was entirely a reactive decision and could only be made because the hospice had a prescribing Advanced Clinical Practitioner, who had been practising for 18 months in that role.

One year later in 2011, the hospice was fully operational in both its inpatient and day therapies services and $£ 1,000,000$ credit in the bank. This is the story of innovation in practice where the advanced nurse practitioner role in palliative care has been extended to an autonomous level not practised anywhere else in the UK. From adversity this eightbedded IPU and day therapies hospice now has a service that is economically robust and has been approved and recognised by the Welsh peer review process. Such is the success of the model that the hospice is undergoing a major new build, and expansion of services, funded entirely from its own resources, responding further to our communities' palliative care needs.

The model and its sustainability along with challenges will be discussed. Change in practice, innovation and leadership for nursing within a hospice setting will be explored.

\section{P-212 IMPROVING THE PATIENT'S JOURNEY BY DESIGNING AND IMPLEMENTING A BESPOKE, DEDICATED TRIAGE SERVICE}

Elaine Green, Rebecca Chambers. Ashgate Hospicecare Chesterfield, UK

10.1136/bmjspcare-2017-hospice.237

Background A comprehensive review was carried out in 2013/ 2014 with the support of Macmillan Cancer Support focusing on workforce development for the Palliative Care Specialist Nurse team working in the community. It recommended the provision of a more responsive and accessible service for patients, carers and health are professionals by developing a bespoke, dedicated Triage and 24/7 Advice Line.

Aims To analyse and explore the most effective referral process to deliver a more responsive and accessible service for all patients who are referred to the Palliative Care Specialist Nurse team.

Method In September 2016 a two-year project commenced which involved four phases:

- Understanding current practices

- Analysis of the literature, audits and clinical practice in other hospices

- The transformational phase which included the development of a bespoke robust model, implementation of systems and processes ready for Test and Launch

- Evaluation of the model, impact analysis on the organisation, patient and carer outcomes.

Results The results of the test in May 2017 demonstrated a clear need for a dedicated Triage referral service Monday to 